\title{
SOBRE DIOSES Y JUECES
}

\author{
CECILIA O' NEILL \\ UNIVERSIDAD DEL PACIFICO
}

Recibido: 27-11-2016

Aprobado: 18-03-2016

Vicedecana de la Facultad de Derecho de la Universidad del Pacífico. Es abogada por la Pontificia Universidad Católica del Perú y máster en Derecho por University of Pennsylvania

(Estados Unidos). Es candidata a Doctora por la Pontificia Universidad Católica del Perú. Es árbitro en procesos arbitrales administrados por el Centro de Arbitraje de la Cámara de Comercio de Lima y el Centro de Arbitraje de la Pontificia I Iniversidad

\section{RESUMEN}

A lo largo de la historia, y debido a distintas razones, ha habido distintos tipos de jueces. Hubo jueces "originalistas", para los cuales el Derecho es sinónimo de ley. También abundaron aquellos "vanguardistas", los cuales tenían el agotador trabajo de juzgar absolutamente todo. $Y$ también estuvieron (y están) presentes los "conciliadores", quienes incorporan valores propios de un estado liberal y democrático a la norma jurídica. ¿Qué tipo de juez queremos? ¿Qué clase de juez necesitamos? Utilizando comparaciones, ejemplos y paralelismos entre los distintos tipos de jueces y los dioses y semidioses griegos (Zeús, Heracles y Hermes) y romanos (Júpiter, Hércules y Mercurio), el presente artículo hace una breve reflexión de los tipos de jueces y plantea una solución al problema. Y la respuesta es crucial, ya que la dosis de compromiso de los jueces con el Estado de Derecho dependerá del tipo de rol que se les asigna.

Palabras clave: Francois Ost, modelo herculáneo, juez posmoderno, constitucionalización del Derecho. 


\begin{abstract}
:
Throughout history, and because of different reasons, there have been different types of judges. There were "originalist" judges, for whom the legal system is synonym of Law. Those "avant-gardes", who had the exhausting work of judging absolutely everything, were also abundant. There are also present those "conciliators", who incorporate values from a liberal and democratic State to the legal norm. What type of judge do we want? Which class of judge do we need? Using comparisons, examples, and parallels between the different type of judges and the Greek Gods (Zeus, Heracles, and Hermes) and Roman Gods (Jupiter, Hercules, and Mercury), the following article enters into a reflection about the type of judges and provides a solution for the problem. The answer is crucial, because the commitment of the judges with the rule of law depends on the type of role given to them.
\end{abstract}

Key Words: Francois Ost, herculean model, postmodern judge, constitutionalisation of Law.

¿Son dioses los jueces? Esta pregunta parece banal, con un no contundente como respuesta, si consideramos que los jueces actúan, o deberían hacerlo, basados en una lógica formal y en la aplicación de las leyes, previstas de antemano, a situaciones concretas.

¿Sigue siendo la pregunta banal si tomamos en cuenta el efecto no esperado de las decisiones de los jueces? Olvidándonos por un momento que existe un sistema de garantías ciudadanas que permiten interpelar las decisiones judiciales, o asumiendo por un momento que todos los actores judiciales en la cadena vertical de control toman decisiones erradas, podemos observar que un juez podría decir que lo blanco es negro, o que lo negro es blanco.

Un juez administra justicia. Hacerlo supone una enorme responsabilidad, pero la historia de la humanidad revela que la dosis de compromiso con el Estado de Derecho que desean inocular los jueces a la función que desempeñan dependerá del tipo de rol que les asignamos.

Con los juicios de Nüremberg -además de castigarse terribles atrocidades- se generó uno de los debates jurídicos más enriquecedores, que puso fin a cualquier intento serio de explicar el rol judicial a través del positivismo. Los jueces nazis fueron llevados a juicio. Su defensa fue parecida a la enarbolada por los militares que llevaron a cabo las torturas y ejecuciones: mientras que los militares adujeron haber seguido las órdenes de la cadena de mando, los 
jueces se defendieron alegando que ellos siguieron órdenes: las órdenes impartidas por la Ley. Como meros aplicadores y no creadores del Derecho, decían, se encontraban impedidos de no poner en práctica las consecuencias jurídicas previstas antes del caso concreto: silogismo puro; supuesto de hecho - consecuencia jurídica.

¿Es ese el tipo de juez que queremos? ¿nos podemos permitir contar con jueces autómatas? ¿o pasamos al otro extremo y formamos jueces que suplantan el rol del legislador?: jueces "creativos", que ignoran la voluntad de quienes dieron contenido a la ley.

¿Es posible encontrar un justo medio? ¿Podemos soñar con un juez respetuoso de la ley y de la autoridad, pero que genere predictibilidad en sus decisiones? ¿Podemos soñar con un juez para quien el Derecho no puede estar disociado de los valores liberales y democráticos?

En esto pensaba al preparar el presente artículo, y vinieron a mi mente las interesantes discusiones con el Profesor César Landa en el Doctorado en Derecho en el que vengo participando. Gracias a dichos encuentros conocí el texto del Profesor Francois Ost, Ilamado "Júpiter, Hércules, Hermes: tres modelos de juez" (Ost, 2007).

El dios más importante y destacado de la Grecia clásica fue Zeús o Júpiter, para la tradición romana. Era el padre tanto de los dioses como de los hombres. Era pues el equivalente al padre de familia. Tenía la menuda tarea de supervisar ni más ni menos todo el universo. Para supervisar el universo hace falta contar con poderes (en el mundo moderno hablaríamos de "funciones") de lo más diversos. De allí que Zeus haya sido tan venerado. Entre otros roles, cumplía el de vigilar los juramentos, castigar a los comerciantes deshonestos y vengar las injusticias.

Nótense las palabras "vigilar", "juramento", "castigo", "deshonestidad", "injusticia". Indiscutible pues el carácter jurídico de sus poderes. Siendo el encargado de vigilar el mundo entero, no es difícil imaginar que para hacerlo haya tenido que ocupar una posición privilegiada en las alturas, desde las cuales podía observarlo todo. Dicen que tras vencer en una batalla a los titanes, se repartió el mundo junto con sus hermanos: a Hades le tocó el 
inframundo, a Poseidón las aguas y a Zeus, ni más ni menos que el cielo. Justo el lugar desde el cual se tiene una visión completa de lo que sucede en nuestro mundo.

Zeus (o Júpiter) era un padre de familia bastante machista, conocido por variados y numerosos amoríos. Tuvo entonces muchos hijos, pero no solamente con su esposa Hera. Era padre de Afrodita, de Atenea, de Perseo, de Dionisio, de Helena y de muchos otros, incluyendo a Heracles (Hércules para los romanos) y a Hermes (Mercurio, en Roma). Atención con estos dos últimos.

Hércules, Ilamado Heracles por los griegos, era hijo natural de Zeus. Este héroe o semidiós destacó por su virilidad, orgullo, coraje, vigor sexual, fuerza. Hércules era la prueba evidente de una de las tantas infidelidades de Zeus, de modo que se ganó el odio visceral de Hera, legítima esposa del dios supremo. Aunque con debilidades humanas, Hércules podía realizar la hazaña que fuese. Fue fácil ser admirado y endiosado generación tras generación.

Hermes (Mercurio, para los romanos) era hermano de Hércules, por ser también hijo de Zeus, aunque de señora distinta. También era un semidiós muy popular. Era hermoso como su hermano, pero su fuerza no era "hercúlea", sino ingeniosa y creativa. Hermes era un mensajero y por tanto era quien protegía a los que cruzaban las fronteras. Pero era un mensajero con privilegios, pues podía aparecer en medio de un combate sin que nadie se atreviese a atacarlo. Su rol conciliador y versátil toma sentido si pensamos en él como la conexión entre el mundo de los vivos y de los muertos, entre el mundo de arriba y el mundo de abajo, entre el mundo de los dioses y el mundo de los mortales. Tomen nota de esto: a Hermes se le asignaban las funciones más complejas (no nos referimos en este artículo al hecho que Hermes sea el dios de la astucia, los ladrones y los mentirosos).

¿Qué tipo de juez queremos? ¿Un juez originalista como Júpiter o Zeus? ¿Un juez vanguardista como Hércules o Heracles? ¿O un juez conciliador como Hermes o Mercurio? 
¿Por qué sería "originalista" un juez inspirado en Júpiter o Zeus? Bajo su cosmovisión, el Derecho es sinónimo de ley. El Derecho se impone desde arriba hacia abajo y no se modifica según el signo de los tiempos, sino según la decisión de la persona investida del poder. La forma ideal de representar este modelo es con una pirámide, que despliega e irradia sus efectos desde arriba hacia abajo, y no al revés. Si hacemos viajar a Júpiter a través del tiempo, estaría contento con las Facultades de Derecho tradicionales y positivistas, que endiosan el carácter sagrado de la ley y la codificación del sistema jurídico, aislado de los valores y principios.

Este modelo de juez supone "la existencia de una autoridad imaginaria que quiere esa norma. Esto es, sin duda, una ficción, pero una ficción necesaria para la validación positivista de los órdenes jurídicos en vigor" (Ost, 2007: p. 106).

Este paradigma de la pirámide y de la codificación entró en profunda crisis en el siglo XX, luego de la Segunda Guerra Mundial.

Heracles o Hércules se habría sentido orgulloso de superar al padre, aportando un modelo judicial inspirado más bien en su fuerza sobrenatural. "El modelo herculáneo, aplicado sobre la tierra, toma la figura de revolución gesto iconoclasta que hace del hombre, más concretamente del juez, la fuente del único Derecho válido" (Ost, 2007: p. 102). Si le pidiéramos a Ronald Dworkin, el filósofo norteamericano que representa la visión hercúlea del Derecho, que dibuje un símbolo que aluda a esta corriente, también dibujaría una pirámide, pero invertida, o más bien un embudo.

Así, el juez es un semidiós que se somete al agotador trabajo de juzgarlo todo: desde el incumplimiento de un contrato hasta el establecimiento de un régimen de visitas, desde revisar todas las decisiones de la administración pública, hasta analizar una interrupción voluntaria del embarazo, desde decidir si pueden casarse personas del mismo sexo, hasta salvaguardar el equilibrio ambiental, desde decidir si se preservaron los derechos de los accionistas de una compañía para aumentar el capital, hasta decidir si debe o no hacerse una transfusión de sangre respetando una objeción de conciencia. $Y$ esta lista sigue. 
A diferencia de la generalidad positivista, con Hércules no importa tanto la abstracción de la ley sino más bien lo singular de cada situación. A diferencia del juez burócrata y autómata, nos encontramos con un juez activista y muchas veces polémico.

Una tercera opción de modelo judicial es el inspirado en Hermes. ¿Queremos entonces un juez conciliador? Recordemos que Hermes es el mediador universal. En vez de dibujar una pirámide o un embudo, Ost sugiere dibujarlo con una red: la idea es integrar puntos, siendo éstos no solamente las leyes o decisiones judiciales, sino incorporando además los valores que inspiran a las leyes, la doctrina, las costumbres, las fuentes de Derecho Internacional, etc.

Hermes representa a un juez posmoderno, que ya ha transitado por el automatismo indiferente del juez Júpiter y por la inseguridad generada por el juez Hércules con sus decisiones impredecibles.

Habíamos dicho que a Hermes se le asignaban las funciones más complejas. Ello es así, pues Hermes, el juez mediador, logra una combinación ideal de autoridad y de valores. No concibe al Derecho como sinónimo de ley, sino que incorpora en la noción de norma jurídica a los valores que inspiran un estado liberal y democrático. Un juez Hermes no pretende acumular poder, sino que reconoce una red de decisores según sus competencias y deja al poder judicial intervenir si no queda más remedio. El juez Hermes debe aplicar la ley, pero a la luz de la Constitución, que no solo funda un sistema jurídico sino además político y de valores.

Con jueces inspirados en Hermes el Derecho es estable y a la vez efímero, es duro y a la vez blando, o en realidad líquido. Asimismo, Ost se pregunta: ¿Es realmente una casualidad que los alquimistas de la Edad Media dieran el nombre de "mercurio", equivalente latino del Hermes griego, a un metal tan particular? (Ost, 2007: p. 121).

Si hubo alguien alejado de una visión líquida de la justicia, fue Kelsen, quien enarboló la teoría pura del Derecho. Esta era definida por un positivismo que fue resultado de la absoluta identidad entre Estado y Derecho. Y curioso que Kelsen, como Júpiter, representase el ordenamiento jurídico como una pirámide, en cuyo tope se encuentra la norma máxima: la Constitución, pero 
desprovista de elementos axiológicos. Así, para Kelsen una ley injusta podía ser anulada pero no por su injusticia, sino por ser contraria a la Constitución (Barberis, 2015: p. 245).

Con la segunda Guerra Mundial cambia la visión kelseniana del Derecho, en virtud de la cual ser juez era una función absolutamente formalista, casi como poner sellos en una mesa de partes: el juez estaba al servicio del legislador.

El Derecho moderno ha superado esta visión, y le ha conferido protagonismo no solamente a las normas, sino además a los hechos, reconociendo así el carácter práctico del Derecho.

Así, para Gustavo Zagrebelsky,

El caso no puede comprenderse jurídicamente si no es por referencia a la norma y ésta por referencia a aquél, pues no es sólo el caso el que debe orientarse por la norma, sino también la norma la que debe orientarse al caso. (...) Tomar en consideración exclusivamente los casos daría lugar a una pura y simple "casuística", incompatible con la existencia del derecho como ordenamiento; tomar en consideración exclusivamente el ordenamiento conduciría a una ciencia teorética, inútil para la finalidad del derecho. (Zagrebelsky, 2011: p. 132).

El debate en la Filosofía del Derecho actual es entre autores post positivistas, para los cuales existe una necesaria conexión entre el Derecho y la justicia, entre el Derecho y los valores. Los principios son ingredientes fundamentales para entender el Derecho.

En efecto, "el modelo de la justicia constitucional kelseniano puro y simple ha sido superado, en la medida que en el texto Constitucional no solo existen derechos fundamentales sino también principios constitucionales y valores superiores" (Landa, 2013: p. 19).

Esto ha generado la llamada constitucionalización del Derecho: todos los operadores jurídicos deben llenar las categorías jurídicas, incluso no constitucionales, a la luz de la Constitución. Así por ejemplo, nociones civiles clásicas como orden público, buena fe o abuso de derecho, deben ser 
interpretadas a la luz de un ejercicio correcto de la ciudadanía, inspirado en los valores constitucionales.

Una visión moderna, liberal y democrática del proceso judicial no tiene al juez como personaje protagónico, pues son las partes las dueñas del proceso, mientras que el juez es su director.

Lo anterior no es incompatible con que, respetada la pluralidad de instancias, los jueces tienen la última palabra y sus decisiones son ejecutables incluso por la fuerza, pero con el propósito de hacer respetar el principio de autoridad y la seguridad jurídica. No es la fuerza por la fuerza, sino el remedio contra la inaceptable decisión de no respetar a la autoridad.

Un juez propio de un estado constitucional busca resolver los problemas, procurando el consenso, el diálogo. Se quiere un juez activista, con iniciativas procesales, pero que no sustituya a las partes, pues perdería su imparcialidad, sin la cual no podemos hablar de un Estado de Derecho.

Es una función del Derecho decir quién tiene qué, quién hace qué y quién es quién (Ost, 2007: p. 130). El instrumento a través del cual ello se logra es el Juez Hermes, que para conciliar debe ser ponderado y sustentar sus decisiones con una adecuada argumentación.

Borges decía que existen infinitas biografías verdaderas de un mismo hombre. ¿Qué tiene que ver esto con los jueces? Mucho. Un juez conciliador pondera tanto las leyes como las circunstancias. Y las circunstancias concretas las conoce por los hechos que relatan las partes.

Es más fácil perder un caso por hechos que por normas, pues las partes no necesariamente cuentan lo que pasó diciendo la verdad. Sin embargo, la verdad del hecho es una condición necesaria de justicia y legalidad de las decisiones. Como señala el Profesor Michelle Taruffo, no hay decisión justa si los hechos son equivocados. Esto, reconociendo que no hay verdad científica absoluta, sino que ésta depende de la cantidad y calidad de la información con la que contamos (clase dictada por el Profesor Michelle Taruffo en el Doctorado en Derecho de la Pontificia Universidad Católica del Perú del 21 de abril de 2016). 
Acá juega un rol fundamental un juez Hermes, conciliador, que actúa inspirado en el debido proceso y en el concepto de igualdad de armas, para permitir a ambas partes, en igualdad de condiciones, aportar material probatorio para que el juez reproduzca la verdad, y solo después de eso, aplique el Derecho al caso concreto.

A pesar de todo lo anterior, si el juez aplica una norma injustamente, es necesario cumplirla, pues si bien el Derecho tiene un fuerte componente valorativo, si no tuviera un componente autoritario dejaría de ser Derecho y se movería solo en el plano de la moral. Por cierto, ello no removería el carácter de incorrección ética e incluso incorrección jurídica de las decisiones judiciales.

Como quiera que el conflicto se acaba con cualquier decisión, aunque no se diga la verdad, el reto es evitar que el juez (en última instancia) diga que lo negro es blanco o que lo blanco es negro. Para ello hace falta un modelo institucional que provea a la organización del Estado de candados de seguridad, como por ejemplo, un mecanismo saludable de elección de los jueces, la lucha anticorrupción y sistemas de control constitucional eficientes.

De hecho, un adecuado modelo institucional para organizar el Estado aumentaría la predictibilidad de las decisiones judiciales, lo que en buena cuenta permitiría anticipar cómo se comportarán los ciudadanos y los agentes económicos.

Como señala Douglas North, la historia revela que desde el inicio de los tiempos el ser humano se ha enfrentado a fenómenos científicos y sociales que no ha podido explicar (North, 2005: 16). Una fuente para aplacar la impotencia ante la falta de entendimiento y de predictibilidad de los fenómenos humanos han sido las religiones, los oráculos y los dioses, que para cumplir sus funciones solían estar acompañados de ritos misteriosos.

Esta percepción de incertidumbre y de misterio se ha venido reduciendo a través de los siglos, gracias a la acumulación de conocimientos y a la tecnología. Pero otra respuesta para la falta de certidumbre la ha brindado el Derecho y sus interlocutores directos: los jueces, que luego de llegar a poner 
en práctica hasta severas ordalías, han terminado racionalizando sus decisiones con el paso del tiempo.

Los jueces jugaron inicialmente un rol absolutista y represivo, derivado de la autoridad política o del poder religioso. El paso del tiempo ha generado el desarrollo de instituciones jurídicas, como las libertades individuales, la propiedad y los contratos, que no hubieran podido consolidarse sin jueces Hermes.

Los jueces ya no son dioses, pero a veces se desvían de su misión y terminan usando poderes sobrenaturales, que convierten lo blanco en negro y lo negro en blanco. No usan capas ni chisteras de mago, pero sí togas o medallas, como rezagos de una distinción respecto de nosotros, los simples mortales.

Sin soslayar su autoridad, en un Estado de Derecho los jueces no pueden ni deben suscitar temor reverencial, puesto que la modernidad ha traído consigo la reducción de la incertidumbre a través del desarrollo democrático, cuya función primordial es generar predictibilidad, incluso de las decisiones judiciales.

\section{BIBLIOGRAFÍA}

Barberis, Mauro. (2015) Juristas y Filósofos. Una Historia de la Filosofía del Derecho. Primera edición. Lima: Editorial Communitas.

Landa Arroyo, César. (2013) "La constitucionalización del derecho peruano". Derecho PUCP. Vol. 71. Lima, pp. 13-36.

North, Douglas. (2005) Understanding the Process of Economic Change. New Jersey: Princeton University Press.

Ost, Francois. (2007) "Júpiter, Hércules, Hermes: Tres modelos de juez". En: Academia. Revista sobre Enseñanza del Derecho. Universidad de Buenos Aires. 
Dirección:

http://www.derecho.uba.ar/publicaciones/rev_academia/revistas/08/jupiterhercules-hermes-tres-modelos-de-juez.pdf

Zagrebelsky, Gustavo. (2011) El derecho dúctil. Décima edición. Madrid: Editorial Trotta. 